\title{
Hotspot Development Path in the Field of Art Design: A Social Network Analysis Approach
}

\section{Oswin Aganda*}

School of Management, Jiangsu University, Zhenjiang, PR China

\begin{abstract}
In order to find out the development trend of Chinese art design discipline, a key network in the field of art design was constructed using social network analysis method to conduct an in-depth analysis of the evolution path of China's research hotspots in art design. This paper uses the Bicomb and the Netdraw software to extract high-frequency key themes and to draw the key themes co-occurrence social network in the field of art design respectively. The key themes in the field of art design were classified and summarized into three stages from 2003 to 2007, 2008 to 2010 and from 2011 to 2016 . The results showed a diversified research direction of China's art design, and many fields such as traditional art, environmental art and information art design were beginning to receive great attention. However, teaching and innovation have been the focus of attention in the field of art design. In addition, the correlation between research directions in the field of Chinese art design is gradually increasing and the key network shows a special small-world effect. But, there was yet to be any significant alliance among the research topics.
\end{abstract}

Keywords: Art design; Social network analysis; Research hotspot; Evolutionary path

\section{Introduction}

There is the claim that artists do not pursue, but find; thus, capturing the real meaning of art's doing and how in doing art, we learn. Art has always been an integral element of well-being in human life. Through art, people gain aesthetic, intellectual and emotional experiences that may lead to new insights about the human condition, their own place in the community and as part of a world. However, the significance of art is not limited merely to the narrow sphere of individual people's lives. In addition, art has always held importance as a statement in any public debate in favor of a society with more openness and more civilized and humane values. Art can provide a critical reflection of the objectives and values of other sectors in society. Art holds at its core a fundamental value that is free of materialism, and for that reason, it has become a powerful voice in opposition to a world that tends to focus on financial and economic values alone [1].

Despite the long tradition of historical, philosophical, and critical inquiry into art design that extends from antiquity to the present, it is fair to say that systematic, institution-wide research programs in these areas are a relatively new in China as well as many other countries in Asia and elsewhere around the world.

Since the industrial revolution, the concept of arts design has gone through the process of arts and crafts, art nouveau, decorative arts, modernist design and postmodern design movement [2]. With the official introduction of China's art design evolution as a first-class discipline in 2012, the development trend in the field of art design has gradually become the focus for scholars [3].

This is partly as a result of the changing status in the field of art designs in the later periods of the twentieth century as they were transformed from being institutions for the professional development of artists and performers to becoming universities of higher learning, with the concomitant expectation that the work of faculty and students should be assessed not only in terms of a body of creative making and performance but in terms of reflection and the systematic development of theory and explanation of the creative enterprise [4].

\section{Social Network Analysis}

Some researchers began to pay attention to social network relations in the 1930s, but it was not until the 1970s that the concept of social network analysis was really proposed. "Social network" refers to a collection of social actors and their relationships. Social actors can be individuals, groups, organizations and countries. Social network analysis is concerned with the interaction between social actors and other Characterization [5].

Social network analysis (SNA) is the process of investigating social structures through the use of networks and graph theory [6].

It is also a social structure made up of a set of social players (such as individuals or organizations), sets of dyadic ties, and other social interactions between players. The social network perspective provides a set of methods for analyzing the structure of whole social entities as well as a variety of theories explaining the patterns observed in these structures [7].

The rest of the paper is organized as follows. After the introduction, section 2 gives a brief literature review of various research work conducted in the field, section 3 explains the research methods and data sources used for this research. The results and discussions are presented in section 4 , then section 5 concludes with some recommendations.

\section{Literature Review}

Presently, researchers have done some study on related subjects in the field of art design. Based on the perspective of innovation and development of art design profession in colleges and universities, Zhang Siliang and Qu Han deconstruct the inheritance system of

*Corresponding author: Oswin Agenda, School of Management, Jiangsu University, Zhenjiang, PR China, Tel: +86 5118878 0011; E-mail: 5103170205@stmail.ujs.edu.cn

Received May 01, 2018; Accepted May 06, 2018; Published May 15, 2018

Citation: Aganda O (2018) Hotspot Development Path in the Field of Art Design: A Social Network Analysis Approach. Arts Social Sci J 9: 364. doi: 10.4172/2151. 6200.1000364

Copyright: (c) 2018 Aganda O. This is an open-access article distributed under the terms of the Creative Commons Attribution License, which permits unrestricted use, distribution, and reproduction in any medium, provided the original author and source are credited. 
folk art design education in China [8]; Hongbo sorts out the training model of art design talents in China under the information age [9]; Zhi explored the development of China's environment art design specialty in the new media era [10]; Yuehong discussed the integration of design thinking and movie art [11]; Yong conducted a theoretical analysis in art design education in the context of an innovative country [12]; Jing conducted an in-depth analysis of the practice teaching mode in the field of art design [13]; Wang Jian unearthed the bottleneck problem in the development of public art education in China [14]; Bin's study on the development of visual communication art, revealed the relevance between the principle and innovation of ethnic art designs [15].

There are also a few researchers who have applied the social network analysis method within disciplines of art design. Amongst them, Xiumei and Fan tracked the hot issues of the research on the strategic planning of libraries in the field of library and information industry based on the key theme system cluster analysis [16]; Huangfu Qinghong and Hua Weina et al. used social network analysis methods to analyze the international figures hotspot topics in the field of library science and author groups [17]; the key themes of China's think-tanks are listed in detail in the key themes co-occurrence and social network analysis methods conducted by Yili et al. [18].

From the existing research results, we can see that the social network analysis method is suitable for the study of hotspot topics within the various disciplines. Therefore, this paper applies the social network analysis method to study the feasibility and applicability of hotspot evolution path in the art design fields.

To sum up, the existing research has these characteristics: First, there are more theoretical discussions on art design than empirical research; secondly, even though there are more research works on art design in majority of its fields, its systematic exploration trend is less. Thirdly, this study provides a number of significant contributions and implications for both academics and practitioners, thus, from an academic perspective, it addresses an acknowledged gap and emerging key theme in knowledge management. Successful knowledge transfer has been seen as vital for organizational versatility, innovation, and competitiveness. In addition, the concepts of social network analysis are still young and therefore under constant development, hence, researching into this area adds methodological knowledge to current field of art design and SNA literature. Therefore, this paper uses social network analysis methods to sort out the hotspot issues and tries to study the evolution path of knowledge innovation in the field of art design in China, and thus this basis systematically studies the development law of art design China.

\section{Methodology and Sample Selection}

\section{Sample selection and data sources}

The data for this paper was from the "China National Knowledge Network" (CNKI) database which contains academic materials that reflect the latest research directions within disciplines and industries. To explore the evolution path of research hotspots in the field of art design, this paper uses "art" and "design" for the title, then CSSCI papers related to art and design were retrieved from the CNKI database. A total of 1,560 documents were retrieved (as at the end of 2016). All the data in this article comes from the CNKI database.

\section{Results and Discussions}

\section{Analysis of innovation in the field of knowledge}

Statistics on the number of theses in the field of art design (Figure 1) show that the number of papers in the field has been quite small from 2003 to 2007, indicating that innovation in the field of knowledge under the field of art design was yet to receive the needed attention resulting in the low enthusiasm for innovation in the field of knowledge. From 2008 to 2010 the innovation in the field of knowledge started to gain attention. During this period, the number of papers in the area of art design showed an explosive growth, reaching its peak in 2010. Due to the support of the China's macroeconomic policies, the number of topics in the field of art design increased dramatically. As a result, the enthusiasm for innovation in the field of knowledge gradually increased. The holding of the Olympic Games and the World Expo has also increased the market demand in the field of art design (such as emblem and venue design, etc.), as a result, the activities in the field of art design also became extremely active during that period.

However, after 2010, the number of papers in the field of art design began to decline, but stabilized and became high after 2012 due to the official introduction of the discipline in art design. The development of the disciplines in the field of art design has now been well established with institutional documents, so knowledge innovation in these related fields are now well planned with a stable overall performance. The overall trend of the number of co-authors in the field of art design was almost the same as that of the total number of papers, from 2003 to 2007, but dropped in comparison with the number of paper from 2008. From that period co-authored papers was relatively small and fairly dropped in 2010. This shows that there was more focus on knowledge cooperation and innovation in the field of art design, thus, open collaborative innovation has now become a new form of knowledge innovation in the field of art design (Figure 1).

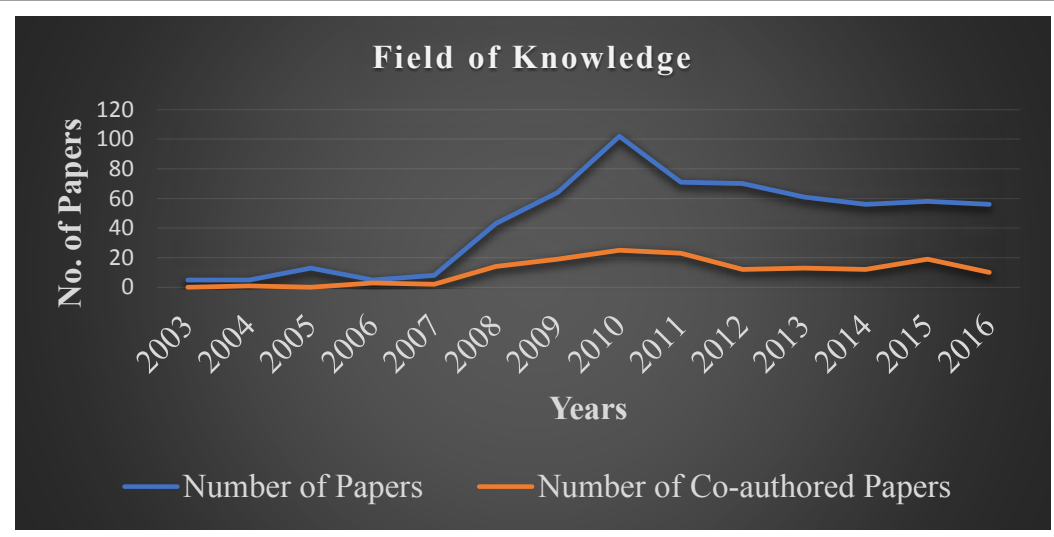

Figure 1: Design innovation in the field of knowledge. 
From Figure 1 and the previous analysis, we can see that the number of papers in the field of art design can be divided into three phases. The first phase was from 2003 to 2007 and the number of papers at this stage was quite low. The number of papers in the second stage from 2008 to 2010 began to grow rapidly but unfortunately in the third stage from 2011 to 2016 the number started to decline even though it remained at a high level. In this paper, the key themes in the field of art design were classified and summarized according to three stages from 2003 to 2007, 2008 to 2010 and from 2011 to 2016. To extract the highfrequency key themes in the field of art design the Bicomb software was used. In addition, the Netdraw software was used to draw the social network diagram of the co-occurrence key themes in the field of art design (Figures 2-4).

The statistical parameters of the network structure evolution feature of the key themes in the field of art design domain are calculated (Table 1). From Table 1, it can be seen that the knowledge cooperation network in the design domain exhibits the following development characteristics.

After the network structure parameter analysis, the following were observed:

\section{Research themes tend to be diversified}

Table 1 shows that the number of network nodes in the first stage is 17 , indicating that at this stage there were fewer high-frequency key themes in the field of art design, and the research direction was quite narrow. The number of network nodes in the second stage increased to 27 , signifying a drastic upsurge of the high-frequency key themes in the field of art design for 2008-2010, showing a diversification of the research topics. For example, in the second stage, hotspot research directions such as information art, modern art, ceramic art and packaging design emerged for the first time. The number of network nodes in the third stage was not much different from the number of network nodes in the second stage, indicating that since 2008 , the breadth of research in the field of art design has remained fundamentally stable.

\section{The research topics were more related, but they did not show any significant correlations}

Network density is an important indicator for the closeness of network members. From Table 1, the network density in the first stage was 0.2426 , it increased to 0.2821 in the second stage, then in the last stage the network density increased again to 0.3400 . This shows that the significance between hotspot research topics in the field of art design was gradually growing, and the research topics could be integrated effectively. This aspect can promote multi-subject and cross-theme innovation research in the field of art design. Knowledge cooperation

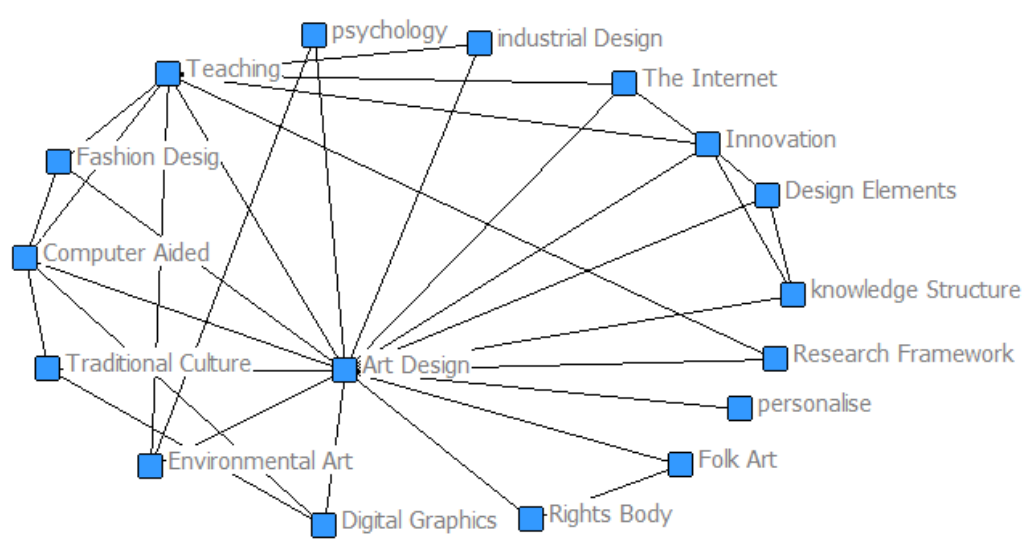

Figure 2: 2003-2007 design domain key theme network.

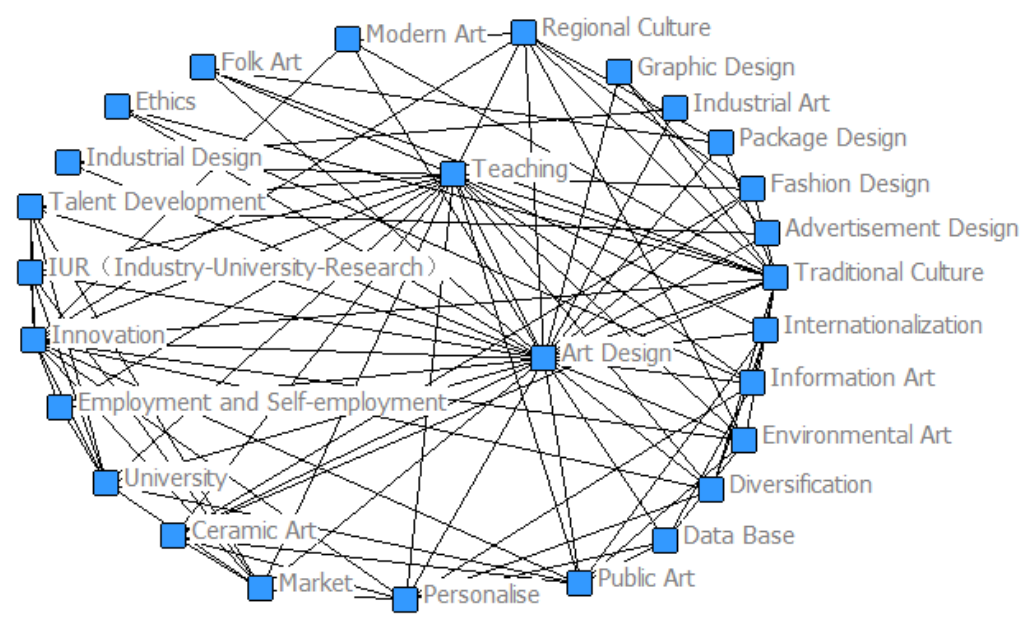

Figure 3: 2008-2010 design domain key theme network. 


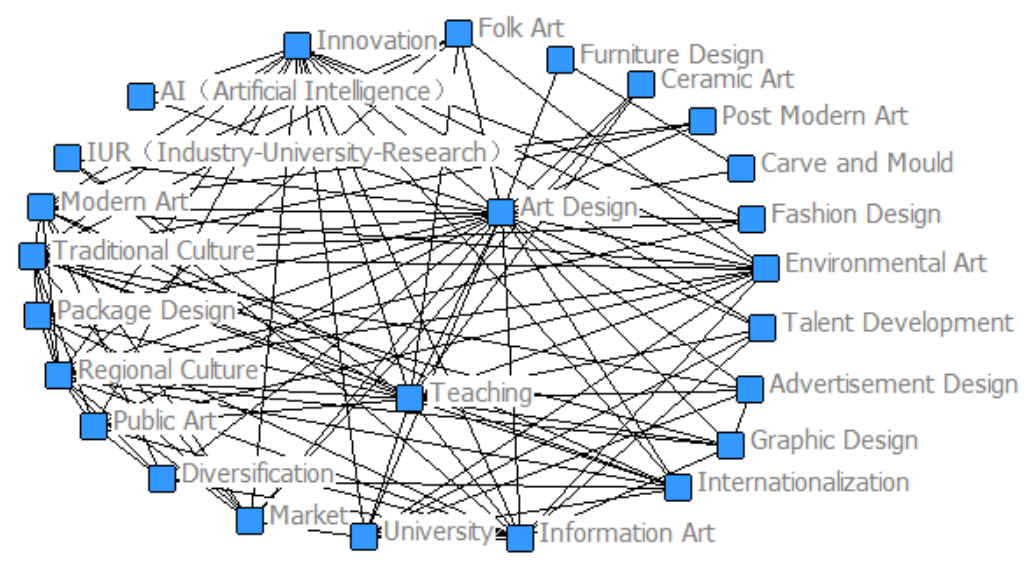

Figure 4: 2011-2016 design domain key themes network.

\begin{tabular}{|c|c|c|}
\hline Variable & $\mathbf{2 0 0 3 - 2 0 0 7}$ & $\mathbf{2 0 0 8 - 2 0 1 0}$ \\
\hline Number of network nodes & 17 & 27 \\
\hline Network density & 0.2426 & 0.2821 \\
\hline Average distance & 1.757 & 1.718 \\
\hline Clustering coefficient & 0.833 & 0.706 \\
\hline The largest K core & 3 & 6 \\
\hline
\end{tabular}

Table 1: Network structure parameter measurement table.

between research directions offers different possibilities. In combining the maximum K-number of cores, it can be seen that the maximum number of K-cores in the field of art design was only 6 , indicating that no large-scale groups have been formed between research themes in the field of art design. It can also be seen that the cooperation and docking mechanisms between the research themes in the field of art design were not mature enough, hence, the research themes with high significance did not show any groupings. This also indicates that the key theme network in the field of art design was starting to emerge suggesting much room for cooperation between the scattered topics and the research topics with higher correlation.

\section{Has a small-world effect}

The small-world effect has the following characteristics: the network is sparse, decentralized, and highly clustered. From the visual network diagram, it can be judged that the knowledge cooperation network in the design domain has the characteristics of small-world. However, for the sake of accuracy, this paper formalizes the smallworld phenomenon of the key theme network in the field of art design. The feature path length and clustering coefficient are the main variables used to measure the small-world effect of the network. If the average distance of a network is short (not more than 10) and the clustering coefficient is high, then the network could be considered as a smallworld effect. From Table 1, we can see that the average distances of the three phases of the keyword network in the design domain were $1.757,1.718$, and 0.660 , and the clustering coefficients were 0.833 , 0.706 , and 0.746 respectively. The average distance of the network was small and the clustering coefficient was high, thus, the network had the characteristics of a small-world network. This shows that there were different degrees of correlation between the research themes in the field of arts design, and a possibility of cooperation between the various research directions in the field.

\section{Measurement of Centrality of Key Themes}

In order to explore the evolution path of research hotspots in the field of art design, this paper measures the degree of centrality of the key themes in the field of art design (Table 2). If the relative degree of a certain key theme is higher, the more important the key theme is in the web. This indicates how intense the research direction is. The relative point centrality is calculated as $C\left(n_{i}\right)=\frac{d\left(n_{i}\right)}{n-1}$, where: $C n_{\mathrm{i}}$ represents the relative degree of node $n_{i}, n$ the total number of nodes $d\left(n_{i}\right)$ represents the absolute degree of center of node $n_{\mathrm{i}}$, and its calculation formula is: $d\left(n_{i}\right)=\sum_{j} X_{i j}, X_{i j}=0$ (when node $\mathrm{n}_{\mathrm{i}}$ is not directly adjacent to $\mathrm{n}_{\mathrm{j}}$ ), $\mathrm{X}_{\mathrm{ij}}=1$ (when the node $\mathrm{n}_{\mathrm{i}}$ is directly adjacent to the $\mathrm{n}_{\mathrm{j}}$ ). In addition, in order to accurately analyze the relevancy between key themes, this paper deletes the associated path whose weight value was less than 5 in the key themes network to filter out the more relevant key themes (Figure 5). From Table 2 and Figure 5 we draw the following conclusions:

Teaching and innovation has always been a research hotspot in the field of art design

From Table 2, we can see that in the first stage, the relative degrees of teaching and innovation are 11.364 and 5.114 respectively (ranked $2^{\text {nd }}$ and $4^{\text {th }}$ ). In the second stage, the relative degrees of the centrality of their relative points are 6.935 and 2.681 respectively (ranked $2^{\text {nd }}$ and $4^{\text {th }}$ ). In the third stage, the relative degrees of their centrality are 8.477 and 4.777 (ranked $2^{\text {nd }}$ and $3^{\text {rd }}$ respectively). In the three stages, the degree of centrality in teaching and innovation has always been ahead, indicating that in the field of art design more attention is being given to issues related to teaching and innovation. From Figure 5, we can see that in the first stage, teaching has received attention in the field of art design, but the correlation with other research themes were poor. In the second stage, teaching and innovation generated a strong relationship between 


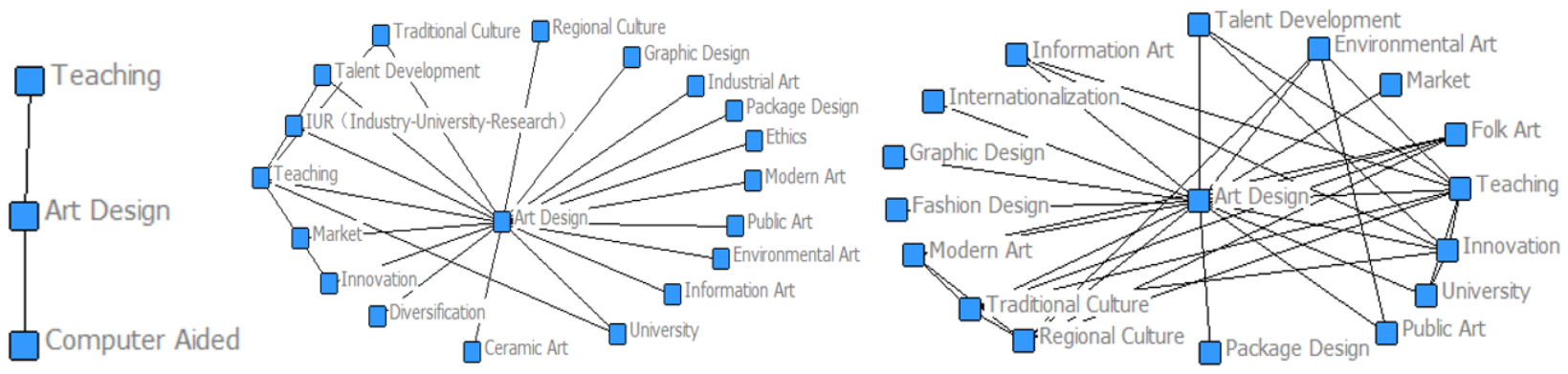

Figure 5: Design domain high relevance keyword network.

\begin{tabular}{|c|c|c|c|c|c|c|}
\hline \multirow[t]{2}{*}{ Ranking } & \multicolumn{2}{|c|}{ 2003-2007 } & \multicolumn{2}{|c|}{ 2008-2010 } & \multicolumn{2}{|c|}{ 2011-2016 } \\
\hline & Key themes & $\begin{array}{l}\text { Relative degree } \\
\text { point of centrality }\end{array}$ & Key themes & $\begin{array}{l}\text { Relative degree } \\
\text { point of centrality }\end{array}$ & Key themes & $\begin{array}{l}\text { Relative degree point } \\
\text { of centrality }\end{array}$ \\
\hline 1 & Art Design & 22.727 & Art Design & 16.434 & Art Design & 18.211 \\
\hline 2 & Teaching & 11.364 & Teaching & 6.935 & Teaching & 8.477 \\
\hline 3 & Computer aided & 6.250 & Traditional Culture & 3.497 & Innovation & 4.777 \\
\hline 4 & Innovation & 5.114 & Innovation & 2.681 & Traditional Culture & 4.167 \\
\hline 5 & Knowledge structure & 3.409 & Talent development & 2.214 & Regional Culture & 3.520 \\
\hline 6 & Design elements & 3.409 & Colleges and universities & 2.156 & Environmental Art & 2.658 \\
\hline 7 & The Internet & 2.841 & Environmental Art & 1.923 & Information art & 2.586 \\
\hline 8 & Environmental Art & 2.841 & Information art & 1.399 & Modern Art & 2.263 \\
\hline 9 & Traditional Culture & 2.841 & Regional Culture & 0.991 & Colleges and universities & 1.940 \\
\hline 10 & Fashion Design & 1.705 & Public art & 0.991 & Talent development & 1.580 \\
\hline
\end{tabular}

Table 2: Relative degree of centrality measurement table.

colleges and personnel training which showed that the teaching related research in the field of art design focused mainly on two directions. The first being the discussion on the innovation of teaching model, and the second, being the discussion on the innovation of the personnel training model in colleges and universities.

In the third stage, the research hotspots related to teaching and innovation in the field of art design still focused on the two above aspects. The difference was that at that stage, attention was given to the combination of traditional cultural, innovation and teaching model innovation. As a new teaching model, teaching in innovative design was of great importance in promoting the improvement of education and teaching quality and inheriting the fine traditional Chinese culture [19]. China's traditional culture is rich and colorful, hence, combining traditional Chinese culture with teaching reforms provides a channel for the succession of China's outstanding traditional culture. It also infuses a new stream of knowledge for traditional Chinese teaching.

\section{Information art began to emerge}

From Table 2, we notice that in the first stage, the information art has not received much attention in the field of art design but in the second and third stages, the relative point centrality increased from 1.399 to 2.586 respectively (ranking $8^{\text {th }}$ and $7^{\text {th }}$ respectively). This showed a gradual increase in attention in information art since 2008. From Figure 5 we see that from 2003 to 2007, computer-aided technology had become a focus of attention in the field of art design. With the promotion of Internet technology, from 2008 to 2010, information art developed into a separate research direction and began to integrate with art design education after 2011. Presently, some colleges and universities such as Tsinghua University have opened the Department of Information Arts and Design. Information art refers to a new type of discipline that fuses the related theories of information technology and arts, and studies the essence of information art. The department of information art majors have set up courses like animation design, information design, and digital entertainment design for undergraduate programs. At the graduate level, they have established research directions such as interactive art, interactive design, animation creation, and digital game design [20]. The information art is based on information technology, guided by the theory of art, and applies information technology to practical life by using the design principles of art. Currently, many smart phone manufacturers have used information art design to provide users with an exquisite designs and interactive interfaces. With the development of internet technology, information art will attract the attention of more universities. Information art is an interdisciplinary subject with strong application and social practice. In the future, colleges and universities should establish an effective interdisciplinary cooperation mechanism between information technology and art majors, and establish interdisciplinary design of information art. On the other hand, universities and colleges should actively establish a cooperation platform for production, learning and research, and promote the integration of information and art design teaching, research and employment.

Traditional culture and regional culture began to receive attention

In the first stage, the relative degree of centrality of traditional culture was 2.841 (ranked $9^{\text {th }}$ ). In the second and third stages, the relative degrees of centrality were 3.497 and 4.167 respectively (ranking $3^{\text {rd }}$ and $4^{\text {th }}$ respectively). However, in the first stage, the regional culture was yet to become the research hotspot in the field of art design. In the second and third stages, the relative degrees of their centrality were 0.991 and 3.520 respectively (ranked $9^{\text {th }}$ and $5^{\text {th }}$ respectively) indicating that traditional culture and regional culture were now receiving attention in the field of art design. From the perspective of development trends, there was no strong correlation between traditional culture, regional 
culture, and other research topics in the field of art design from 2008 to 2010. Since 2011, research related to traditional culture and regional culture focused on two directions. The first direction was the study on the integration of traditional culture, regional culture and teaching, and the second direction was on traditional culture, regional culture and college art design.

First of all, college art design education is an important carrier for inheriting and carrying forward traditional and regional culture. Traditional and regional culture have rich connotations and regional characteristics, therefore, combining traditional culture, regional culture and art design education can stimulate enthusiasm in students' learning, hence, providing students with new theoretical perspectives and design inspiration. Secondly, art design education can enable students to learn Chinese excellent traditional culture while interacting with cultures around the world on the basis of using the new period of art culture to give new meaning to Chinese traditional culture. Finally, the regional culture has its own characteristics, thus, combining the regional culture with the art design education can promote each regional culture strengths. In the future, colleges and universities should integrate traditional and regional culture into college and universities art design education. In particular, local colleges and universities' art education has the advantages of culture, history, resources, and location in carrying forward the outstanding regional culture. Therefore, it should inherit and promote more excellent regional culture as its own important mission [21].

Another research direction related to traditional culture and regional culture is its integration with modern art design. The integration of traditional regional culture with modern art design can, on one hand, enable local ethnic characteristics in modern art works and increase the meaning and commercial value of the national culture. On the other hand, the close combination of regional features and the sense of the times has given new meaning to regional features [22]. For example, the mascot of the 2008 Olympic Games in China is a perfect example of integrating regional culture with modern art design.

\section{Environmental art design has gradually gained attention}

In the first stage, the relative point centrality of the environmental art design was 2.841 (ranked $8^{\text {th }}$ ); in the second and third stages, the relative point centrality was 1.923 and 2.658 (ranked $7^{\text {th }}$ and $6^{\text {th }}$ respectively). This showed that the environmental art design is gradually receiving attention. From the specific development trajectory, the first stage of environmental art design has not attracted enough attention in the field of art design. From 2008 to 2010, the environmental art design gradually received attention, but there was no strong correlation between environmental art design and teaching since 2011. With the acceleration of the pace of new urbanization in China, people's requirements for the living environment are getting higher and higher. Therefore, the research on the theory and practice related to environmental art design is increasingly gaining some concerns by the academic community. One of the main purposes of environmental art design research is to combine theoretical knowledge with the design of environmental art in real life so that social people can integrate effectively with the natural environment and improve the quality of environment in the human settlement [23]. In addition, there has been fierce contradiction between the construction of ecological civilization in China and urban development. Some viewpoints suggest that urban construction has a destructive effect on ecology, while environmental art design can take into account the ecological and artistic nature of urban planning and optimize urban planning. At the same time, it can also protect and beautify the ecological environment and effectively alleviate the original contradiction between the two. Finally, there are also some problems in the environmental art design education in colleges and universities in China, such as the weakness of the professional disciplines and the uneven quality of the teaching staff. Therefore, how to realize the innovation of the teaching model to solve the existing problems has also become a research hotspot in the field of art design.

From the evolution process of research hotspots in the field of art design, we can see that the research direction in this field is increasingly diversified. With the increasing emphasis on traditional and regional culture in the field of art design, related art design forms such as ceramic art design and folk-art designs have also received attention. In addition, with the commercialization of modern society, the art design forms related to market demand, such as modern art design, public art design, costume design, and package design, have also received attention. Art design is a discipline that focuses on the combination of theory and practice. With the development of economy and the change of market demand structure, the research hotspots in the field of art design should always be updated. In addition, while discussing the forms of modern art, the field of art design it did not abandon China's outstanding traditional culture and art forms. Instead, it chose to combine traditional art with modern art to promote the reinvention of traditional art. The move has given new life to Chinese traditional arts and at the same time it has added some color to China's modern art design forms.

\section{China's art design is gradually becoming international}

As can be seen from Figure 5, since 2011, internationalization has become a research hotspot in the field of art design. Art design profession is a professional with internationalized industry background. It is an inevitable trend toward internationalization [24].

Internationalization can enable China's domestic art design fields to receive the latest overseas trends related to art design at any time, so as to maintain the forward-looking development of the art design discipline in China. Today, many colleges and universities in China have begun to provide bilingual teaching in the field of art design to promote the internationalization of art design education. Bilingual education is a new challenge facing art design education in the context of social information and economic globalization. It is also an inevitable trend of the reform and development of art design education in China. In addition, the traditional international communication of art design is often limited to the exchange between a very small number of overseas students or experts, and the introduction of courses and teaching methods are the main features which are basically passive learning from the West. There is very little extensive communication exchanges, especially between students in schools [25]. In the future, the field of artistic design in China should, on one hand, reform the teaching model and open up bilingual courses in art design majors in universities to lay the language foundation for the exchange of college students abroad. In addition, colleges and universities in China should establish cooperation with overseas universities to provide opportunities for Chinese university students to go abroad for exchange. Chinese students should not only learn the advanced art design knowledge of the West, but also should pass on China's art design culture to the world (Table 2).

\section{Conclusion and Suggestion}

This paper used the social network analysis (SNA) method to analyze the hotspot development path in the field of art design in 
China. The key themes in the field of art design were classified and summarized into three stages from 2003 to 2007, 2008 to 2010 and from 2011 to 2016.

The results showed that the significance between various research themes in the field of art design in China was increasing gradually since 2003, which reflects a gradual deepening in knowledge cooperation and sharing among various research directions. However, there was no significant grouping among research topics with high correlations, hence, there is still a large space for knowledge cooperation between research directions with higher correlation.

With the development of society, the traditional teaching mode of art design has been unable to meet the needs of the market. Therefore, how to reform the teaching model has always been the focus of attention in the field of art design [26]. On one hand, colleges and universities in China should establish the discipline orientation of art design, formulate teaching plans on the basis of this, and take the employment and market demand as guidance, and reform the curriculum system and talent cultivation mechanism. On the other hand, Chinese universities should promptly adjust the training direction of art design professionals and pay more attention to enhancing creativity and social practice ability of students of art design.

As a product of the combination of internet and traditional art design, information art design is gaining more attention. The internet has provided technical support and information channels for traditional art design and solved many problems faced by traditional art. Internet technology has also opened up new directions for traditional art design. In the future, with the development of "Internet Plus," information art will gradually become more professional and international.

The field of art design has entered a period of rapid development and has also become increasingly diversified in the field of related art design since 2008. The research directions such as packaging design and fashion design that were closely related to the needs of the modern market are becoming more and more popular. Traditional art and modern art forms are actively merging and innovating. Environmental art design and public art design also play an increasingly important role with the advancement of new urbanization in China. On one hand, it reflects that China's field of art design has a strong vitality and good prospects for development; on the other hand, it also shows that China's art design field has strong sensitivity and can actively promote art design disciplines in accordance with the characteristics of the times and social development needs. The concept of development of the Chinese art design discipline "Developing with the times and progressing with the society" is also worth studying all over the world.

\section{References}

1. Buchanan R, Nikula ER, Ahlbäck S,Calabrese O, Jeschke C (2009) Research in Art and Design in Finnish Universities. Publications of the Academy of Finland 4: 9.

2. Yanzu L (1996) The 100-year history of modern art and its significance in decoration. Literature and Art Research 5: 111-131.

3. Na L (2017) The Influence of Bauhaus Educational Model on Chinese Design Education: A Review of Heritage and Renewal: Reflections on Chinese Design Education. Chinese Journal of Education.

4. Holt H, Dewey L (1938) The Theory of Inquiry New York.
5. Jun L (2009) Overall Network Analysis Handout: A Practical Guide to UCINET Software. Shanghai: Gezhi Publishing House.

6. Otte E, Rousseau R (2002) Social network analysis: a powerful strategy, also for the information sciences. Journal of information Science 28: 441-453.

7. Wasserman S, Faust K (1994) Social network analysis: Methods and applications. Cambridge university press.

8. Zhang Siliang QZ (2015) The Construction of Educational Inheritance System of Folk Arts: Based on the Perspective of Innovation and Development of University Art Design Majors. Chinese University of Science \& Technology 6 : 38-39.

9. Hongbo Z (2015) The Cultivation of Innovative Talents under the Development of Information Technology: Taking Art and Design Talent Cultivation as an Example. Chinese University of Science \& Technology 5:78-79.

10. Zhi C (2015) Research on the Development of Environmental Art Design in the New Media Age. Guangxi Social Sciences12: 217-220.

11. Yuehong N (2015) Design Thinking Promotes the Development of Film Art. Decoration 5: 12-14.

12. Yong S (2015) Art Design Education in an Innovative Country Background: A Review of the Research on the Development Strategy of Chinese Art Design Education. Chinese Journal of Education.

13. Jing X, Yi XH (2015) Exploring the Multiple Development in Open Experimental Teaching of Art Design. Decoration 5: 96-97.

14. Jian W (2015) Breaking the Bottleneck of the Development of Public Art Education: Based on the Perspective of Cognition, Design and System. Chinese University Teaching.

15. Bin H (2015) Research on National Traditional Design Innovation Based on the Development of Visual Communication Art. Guizhou Ethnic Studies 9: 108-111.

16. Xiumei H, Fan G (2016) Research and Analysis of Library Strategic Planning in the Field of Library and Information Science in China. Library and Information Service 60: 13-17.

17. Hong HY, Weina H, Yanhua L (2013) Analysis of International Digital Library Research Hotspots and Authors Group Analysis Based on Co-word Analysis and Social Network Analysis. Journal of information Science 1: 118-123.

18. Yili J, Wenjing T, Ying D (2015) A Study of Hot Topics in China's Think Tanks Based on Keyword Co-occurrence and Social Network Analysis. Information Science.

19. Xiuling D (2017) The Influence of Innovative Design Teaching on the Inheritance of Traditional Culture: Taking the Case of the Porcelain as Example. Chinese University of Science \& Technology 5

20. Xiaobo L (2010) Review and Prospect: Development of Information and Art Design Professionals. Decoration 1: 30-33.

21. Ruizhi Z, Zefang D (2017) Promoting Outstanding Regional Culture and Innovation of Local Colleges and Universities Art Education. Monthly Journal 2: $41-43$.

22. Li W, Rui Z (2014) Inheritance and Application of Regional Culture in Modern Art Design. Literary Review 9:117-119.

23. Zhongxia $L$ (2016) Environmental Art Design Theory Research and Practica Teaching: A Review of Environmental Art Design. Chinese Journal of Education 1: 116-116.

24. Xinmei T (2017) Research on ESP "Fliping Classroom" Teaching Model fo Postgraduates of Art Design Specialty: Taking Shandong University (Weihai) Art Institute as an Example. Decoration 1: 130-131.

25. Yunling L (2017) International Education Exchange Assisting the Development of Art Design Education: A Review of Design Designer: A Comparative Study of Sino-Finnish Art and Design Education. Chinese Journal of Education 2.

26. Zhenying S (2017) Constructing a Multidimensional Practical Teaching System for Art Design Majors: A Review of China's Art Design Education Development Strategy. Chinese Journal of Education 4. 